\title{
Effectiveness Evaluation of the EWCCS based on the Hybrid Multiple Attribute Decision Making TOPSIS Algorithm
}

\author{
Zong-feng Qi ${ }^{1}$ and Guo-sheng Wang ${ }^{2}$ \\ ${ }^{1}$ The State Key Laboratory of Complex Electromagnetic Environment Effects on \\ Electronics and Information System (CEMEE), Luoyang, 471003, China \\ ${ }^{2}$ Department of Control Engineering, Academy of Armored Forces Engineering, \\ Beijing 100072, China \\ gswang@126.com
}

\begin{abstract}
When evaluating the effectiveness of the electronic warfare command and control system (EWCCS), some special performances can not determine whether the system is good or not. And it is necessary to classify the performances into the qualitative ones and the quantitative ones. Based on the hybrid multiple attribute decision making theory, the qualitative performances are described by some fuzzy langue and expressed by the interval numbers. Based on the new distance formula of the interval number, the hybrid multiple attribute decision making (HMADM) TOPSIS evaluation algorithm is proposed. Finally, an example of three EWCCSs and its simulation results show that the proposed the HMADM TOPSIS algorithm of effectiveness evaluation for the electronic warfare command and control system is simple and effective.
\end{abstract}

Keywords: Effectiveness evaluation; electronic warfare command and control system (EWCCS); hybrid multiple attribute decision making (HMADM); TOPSIS algorithm; interval number

\section{Introduction}

The electronic warfare command and control system (EWCCS) becomes one of important components of equipment systems in modern information battles [1]. Thus it is necessary and important to evaluate the effectiveness of EWCCS. The effectiveness evaluation results can offer some important data for the design, layout and utilization of equipment systems. The performances of EWCCS can be classified into the qualitative ones and the quantitative ones [2], where the qualitative performance scored by the accuracy number can not reflect its actual feature. Thus there is a need to find a new distance formula of the interval number to express the qualitative performance.

The qualitative performance is fuzzy and uncertain. In order to obtain the good evaluation effectiveness, the decision maker often utilizes a fuzzy langue to describe the qualitative performance, and the advantage of the interval number on expressing the fuzzy langue. According to the traditional distance formula of the interval number and the method of undetermined coefficient, a new measurement method for the interval number is presented. Therefore, the HMADM TOPSIS algorithm of effectiveness evaluation for EWCCS is simple and effective, and can obtain the scientific results of effectiveness evaluation. 


\section{Effectiveness Evaluation Performances for EWCCS}

According to the features of EWCCS, many factors associated with the performances of EWCCS can be found out and can be classified into the target hierarchy, the rule hierarchy and the scheme hierarchy ${ }^{[3-5]}$.

The target hierarchy for effectiveness evaluation of EWCCS can be denoted by A. The rule hierarchy of EWCCS includes scouting and detecting ability B1, command and control ability B2, communicating and safeguarding ability B3, and battlefield electromagnetism environment B4. The hierarchy structure between the target hierarchy and the rule hierarchy can be shown in Figure 1.

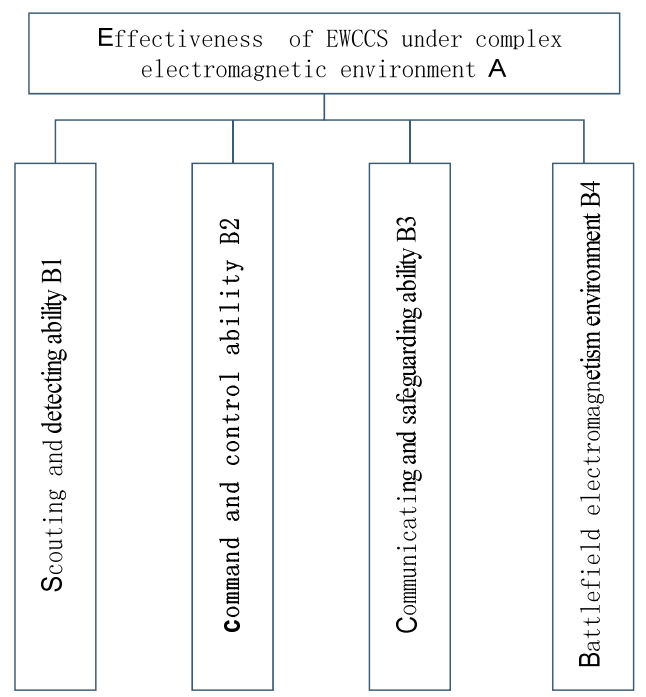

Figure 1. The Hierarchy Structure between the Target Hierarchy and the Rule Hierarchy

The rule hierarchy of scouting and detecting ability B1 includes scouting and detecting method $\mathrm{C} 11$, scouting and detecting range $\mathrm{C} 12$, target density $\mathrm{C} 13$, probability of detecting target $\mathrm{C} 14$, alerting probability of $\mathrm{C} 15$, false-alarm probability of $\mathrm{C} 16$ and ability of identifying target $\mathrm{C} 17$. The hierarchy structure between the target hierarchy B1 and its scheme hierarchy can be shown in Figure 2.

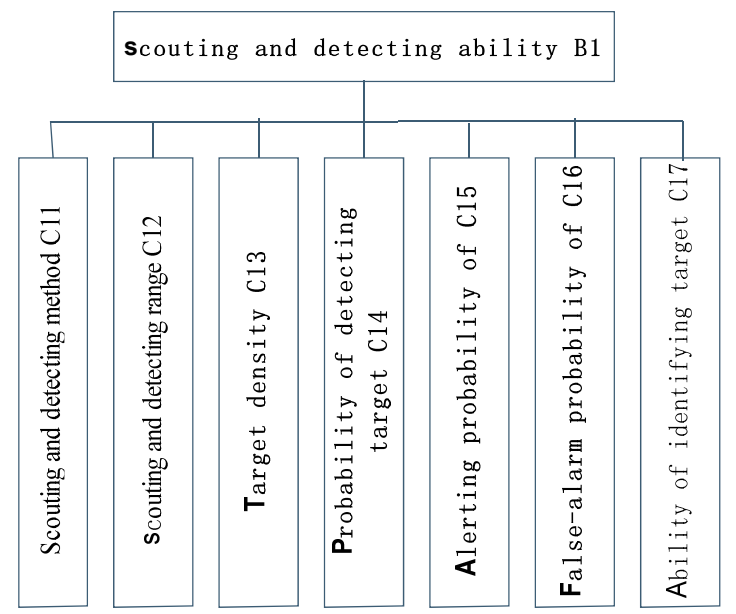

Figure 2. The Hierarchy Structure between the Target Hierarchy B1 and Its Scheme Hierarchy 
The scheme hierarchy of command and control ability B2 include ability of auxiliary decision $\mathrm{C} 21$, decision delay $\mathrm{C} 22$, ability of scientific decision $\mathrm{C} 23$, ability of threat judgment $\mathrm{C} 24$, campaign range $\mathrm{C} 25$, command scale $\mathrm{C} 26$, commanders' capability $\mathrm{C} 27$, and ability of weapon control C28. The hierarchy structure between the target hierarchy B2 and its scheme hierarchy can be shown in Figure 3.

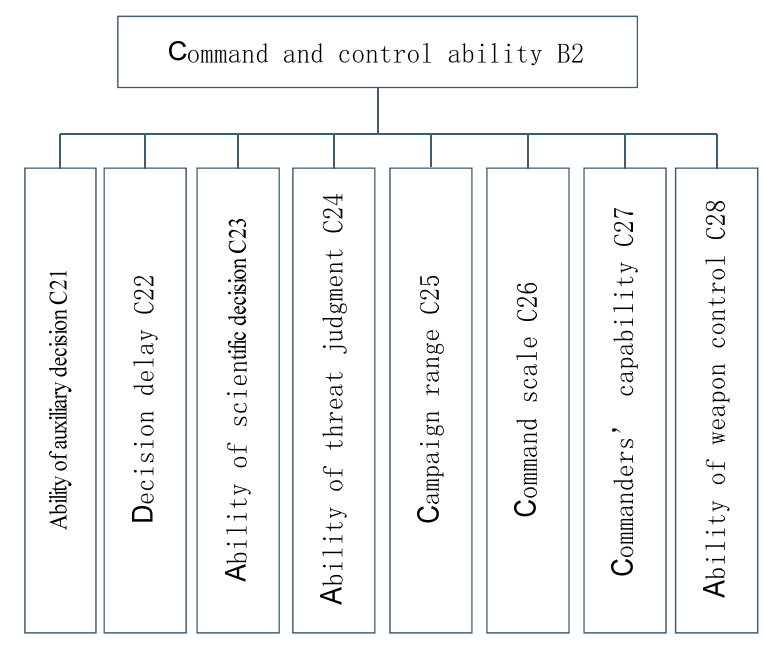

Figure 3. The Hierarchy Structure between the Target Hierarchy B2 and Its Scheme Hierarchy

The scheme hierarchy of communicating and safeguarding ability B3 include covering range $\mathrm{C} 31$, communicating capacity $\mathrm{C} 32$, operation types $\mathrm{C} 33$, miscode rate $\mathrm{C} 34$, communicating delay time $\mathrm{C} 35$, secrecy ability $\mathrm{C} 36$ and interlinkage ability C37. The hierarchy structure between the target hierarchy B3 and its scheme hierarchy can be shown in Figure 4.

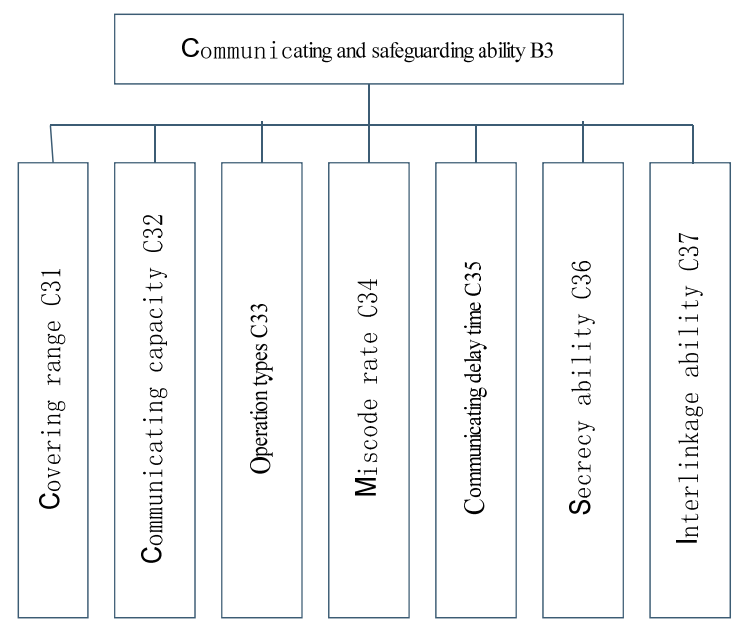
Figure 4. The Hierarchy Structure between the Target Hierarchy B3 and
Its Scheme Hierarchy

The hierarchy structure of battlefield electromagnetism environment B4 includes quality of electromagnetism radiant point $\mathrm{C} 41$, density of electromagnetism signal $\mathrm{C} 42$, intensity of geomagnetism signal $\mathrm{C} 43$, parameters of geomagnetism signal C44. The hierarchy structure between the target hierarchy B4 and its scheme hierarchy can be shown in Figure 5. 


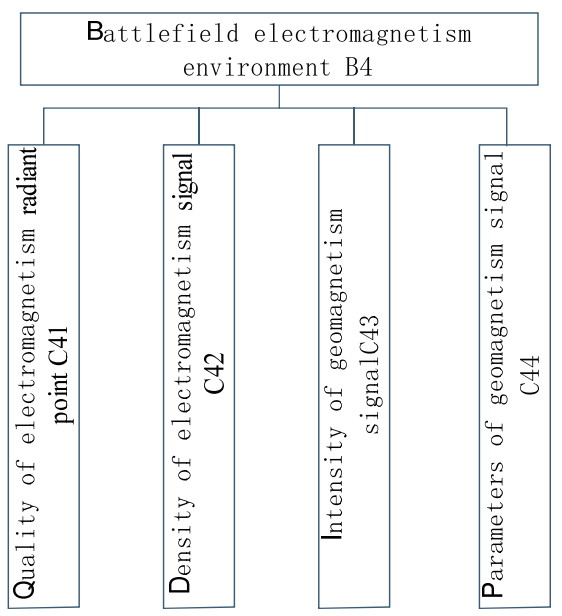

Figure 5. The Hierarchy Structure between the Target Hierarchy B4 and Its Scheme Hierarchy

\section{Handling the Effectiveness Performances}

Assume that there are $m$ EWCCSs to be evaluated and there are $n$ attributes for every EWCCS. Denote the set of the evaluated EWCCSs by $S=\left\{s_{1}, s_{2}, \cdots, s_{m}\right\}$ and denote the set of attributes in the scheme hierarchy of the EWCCS by $U=\left\{u_{1}, u_{2}, \cdots, u_{n}\right\}$, respectively. Determine the attributes' values $r_{i j}(i=1,2, \cdots, m, j=1,2, \cdots, n)$ of every EWCCS in the scheme hierarchy and compute the attribute matrix in the following form

$$
R=\left[\begin{array}{cccc}
r_{11} & r_{12} & \cdots & r_{1 n} \\
r_{21} & r_{22} & \cdots & r_{2 n} \\
\vdots & \vdots & \vdots & \vdots \\
r_{m 1} & r_{m 2} & \cdots & r_{m n}
\end{array}\right]
$$

where $r_{i j}(i=1,2, \cdots, m, j=1,2, \cdots, n)$ can be an accurate (quantitative) number or a qualitative language.

\subsection{The Quantitative Performance}

The quantitative performance can be presented by the accurate number, which can be classified into a benefit performance and a cost performance. The quantitative performance is turned into the interval number by the range method ${ }^{[6]}$, and given by

$$
y_{i j}=\left[y_{i j}^{l}, y_{i j}^{u}\right]
$$

where

$$
\left\{\begin{array}{c}
y_{i j}^{l}=\left(r_{i j}-\min _{i} r_{i j}\right) /\left(\max _{i} r_{i j}-\min _{i} r_{i j}\right), i \in m, j \in n \\
y_{i j}^{u}=1-\left(\max _{i} r_{i j}-r_{i j}\right) /\left(\max _{i} r_{i j}-\min _{i} r_{i j}\right), i \in m, j \in n
\end{array}, r_{i j}\right. \text { is a benefit specification }
$$

and

$$
\left\{\begin{array}{c}
y_{i j}^{l}=\left(\max _{i} r_{i j}-r_{i j}\right) /\left(\max _{i} r_{i j}-\min _{i} r_{i j}\right), i \in m, j \in n \\
y_{i j}^{u}=1-\left(r_{i j}-\min _{i} r_{i j}\right) /\left(\max _{i} r_{i j}-\min _{i} r_{i j}\right), i \in m, j \in n
\end{array}, r_{i j}\right. \text { is a cost specification }
$$




\subsection{The Qualitative Performance}

Because of complexity and uncertainty of the qualitative performances, it is proper to express them by the fuzzy evaluation langue ${ }^{[7]}$. According to [8], 11 level language variables and their corresponding interval numbers can be listed in Table 1.

Table 1. 11 Level Language Variables and their Corresponding Interval Numbers

\begin{tabular}{cccccc}
\hline Level & Good5 & Good4 & Good3 & Good2 & Good1 \\
\hline Interval & {$[1,1]$} & {$[0.9,0.95]$} & {$[0.8,0.9]$} & {$[0.7,0.85]$} & {$[0.55,0.7]$} \\
\hline fair & Poor5 & Poor4 & Poor3 & Poor2 & Poor1 \\
\hline$[0.4,0.6]$ & {$[0.4,0.55]$} & {$[0.3,0.45]$} & {$[0.2,0.3]$} & {$[0.1,0.15]$} & {$[0,0]$} \\
\hline
\end{tabular}

\section{The Effectiveness Evaluation Algorithm}

\subsection{The Weights of the Criteria}

Because the criteria of effectiveness evaluation have diverse significance and meanings, it is not proper to assume that each evaluation criteria is of equal importance. There are many methods that can be employed to determine weights. The AHP method is a very useful decision analysis tool in dealing with multiple criteria decision problems and has been successfully applied to many construction industry decision areas. In this paper, we apply the AHP method to obtain the weights of the evaluation criteria, whose detail steps can be listed as follows: ${ }^{[9]}$

1) Establish the decision matrix $A$

Compare the comparative weight between the attributes of the decision elements to form the reciprocal matrix $A$, where the ratio scale in the AHP is given in Table 2.

Table 2. Ratio Scale in the AHP

\begin{tabular}{ccccccc}
\hline Intensity & 1 & 3 & 5 & 7 & 9 & $2,4,6,8$ \\
\hline Linguistic & Equal & Moderate & Strong & Demonstrated & Extreme & Intermediate value \\
\hline
\end{tabular}

2) According to the above decision matrix $A$, calculate the product $M_{i}$ of all the elements in the each row of $A$ :

$$
M_{i}=\prod_{j=1}^{n} a_{i j},(i=1,2, \ldots, n)
$$

3) Calculate $\sqrt[n]{M_{i}}$ of $M_{i}$ in (5):

$$
\overline{M I}_{i}=\sqrt[n]{M_{i}}, \quad(i=1,2, \ldots, n)
$$

4) Calculate the unitization of $\overline{M I}_{i}$ in (6):

$$
w_{i}=\overline{M I}_{i} / \sum_{j=1}^{n} \overline{M I}_{j}, \quad(i=1,2, \ldots, n)
$$

which is the weight $w_{i}$ of the evaluation criteria $u_{i}$.

5) Test the consistency of the relative importance. In the AHP, the pairwise comparisons in a judgment matrix are considered to be adequately consistent if the corresponding consistency ratio (C.R.) is less than 10\%. The C. R. coefficient is calculated as follows: 
a) The consistency index (C.I.) needs to be estimated. This is done by adding the columns in the judgment matrix and multiply the resulting vector by the vector of priorities (i.e., the approximated eigenvector) obtained earlier. This yields an approximation of the maximum eigenvalue, denoted by $\lambda_{\max }$.

b) The C. I. value is calculated by using the formula: C.I. $=\left(\lambda_{\max }-n\right) /(n-1)$. Next the consistency ratio CR is obtained by dividing the C. I. value by the Random Consistency index (R. I.) as given in Table 3.

Table 3. The R. I. for Different Size Matrices

\begin{tabular}{ccccccccccc}
\hline Number of elements & 3 & 4 & 5 & 6 & 7 & 8 & 9 & 10 & 11 & 12 \\
\hline R. I. & 0.52 & 0.89 & 1.11 & 1.25 & 1.35 & 1.40 & 1.45 & 1.51 & 1.54 & 1.56 \\
\hline
\end{tabular}

\subsection{The Modified TOPSIS Evaluation Algorithm}

TOPSIS was proposed to determine the best alternative based on the concepts of the compromise solution [10-11]. The compromise solution can be regarded as choosing the solution with the shortest Euclidean distance from the ideal solution and the farthest Euclidean distance from the negative ideal solution. The procedures of TOPSIS can be described as follows.

1) For the hybrid multiple attribute decision making problem, the evaluated system $s_{i}$ with the performance set $U$ can be expressed in the form of the interval number:

$$
S_{i}=\left\{\left(u_{1},\left[y_{i 1}^{l}, y_{i 1}^{u}\right]\right),\left(u_{2},\left[y_{i 2}^{l}, y_{i 2}^{u}\right]\right), \cdots,\left(u_{n},\left[y_{i n}^{l}, y_{i n}^{u}\right]\right)\right\}
$$

2) Establish the ideal solution and the negative ideal solution of $S=\left\{s_{1}, s_{2}, \cdots, s_{m}\right\}$ with performance set, respectively, as follows :

$$
s^{+}=\left\{\left(u_{1},[1,1]\right),\left(u_{2},[1,1]\right), \cdots,\left(u_{n},[1,1]\right)\right\}
$$

and

$$
s^{-}=\left\{\left(u_{1},[0,0]\right),\left(u_{2},[0,0]\right), \cdots,\left(u_{n},[0,0]\right)\right\}
$$

3) Calculate the weight distance from every evaluated system $s_{i}$ to the ideal solution and the negative ideal solution, respectively, as follows:

$$
D_{i}^{+}=D\left(s_{i}, s^{+}\right)=\sum_{j=1}^{n} w_{j} D\left(\left[y_{i j}^{l}, y_{i j}^{u}\right],[1,1]\right)
$$

and

$$
D_{i}^{-}=D\left(s_{i}, s^{-}\right)=\sum_{j=1}^{n} w_{j} D\left(\left[y_{i j}^{l}, y_{i j}^{u}\right],[0,0]\right)
$$

where $D$ stands for a new distance between two interval numbers and is given by

$$
D\left(\left[a^{l}, a^{u}\right],\left[b^{l}, b^{u}\right]\right)=\sqrt{\left(\frac{a^{l}+a^{u}}{2}-\frac{b^{l}+b^{u}}{2}\right)^{2}+\frac{1}{3}\left(\frac{a^{u}-a^{l}}{2}-\frac{b^{u}-b^{l}}{2}\right)^{2}}
$$

where $D$ is the newly defined distance between two interval numbers.

4) Based on (11) and (12), calculate the approaching degree $Z_{i}$ as follows:

$$
Z_{i}=\frac{D_{i}^{-}}{D_{i}^{-}+D_{i}^{+}}
$$

where the bigger the value $Z_{i}$ is, the better the effectiveness of the evaluated system is. 


\section{A Numerical Example and Its Simulation}

\subsection{The Weight of Criteria}

Based on the evaluation hierarchy structure of the EWCCS in Figure 1, the GSRA method, we will calculate the effectiveness evaluation of three EWCCSs in Figure 1.

1) Assume that the pair-wise judgment matrix among complex electromagnetic environment include scouting and detecting ability B1, command and control ability B2, communicating and safeguarding ability B3, and battlefield electromagnetism environment B4 can be given by the following Table 4 . And the weight vector of B1, B2, B3 and B4 is $\left[\begin{array}{llll}0.553 & 0.1313 & 0.2704 & 0.0454\end{array}\right]^{T}, C . R .=0.0883<0.1$ shows that the relative importance of the pair-wise judgment matrix is consistent.

Table 4. The Pair-Wise Judgment Matrix among B1, B2, B3 and B4

\begin{tabular}{llllll}
\hline $\mathrm{A}$ & $\mathrm{B} 1$ & $\mathrm{~B} 2$ & $\mathrm{~B} 3$ & $\mathrm{~B} 4$ & $\mathrm{WA}$ \\
$\mathrm{B} 1$ & 1 & 5 & 3 & 7 & 0.553 \\
$\mathrm{~B} 2$ & 0.2 & 1 & 0.3333 & 5 & 0.1313 \\
$\mathrm{~B} 3$ & 0.3333 & 3 & 1 & 6 & 0.2704 \\
$\mathrm{~B} 4$ & 0.1429 & 0.2 & 0.1667 & 1 & 0.0454 \\
$\lambda_{\max }$ & $=4.2359$ & \multicolumn{2}{l}{ C.I. $=0.0786$} & C.R. $=0.0883<0.1$ \\
\hline
\end{tabular}

For simplicity, we directly give the weight of the criteria in the scheme hierarchy associated with those in the rule hierarchy as follows:

$$
\begin{gathered}
W_{B 1}=\left[\begin{array}{llllllll}
0.1601 & 0.252 & 0.3194 & 0.1258 & 0.0369 & 0.0701 & 0.0357
\end{array}\right]^{T} \\
W_{B 2}=\left[\begin{array}{llllllll}
0.1596 & 0.343 & 0.1596 & 0.0666 & 0.1412 & 0.0506 & 0.0393 & 0.0402
\end{array}\right]^{T} \\
W_{B 3}=\left[\begin{array}{lllllll}
0.326 & 0.2674 & 0.0964 & 0.116 & 0.0877 & 0.0494 & 0.0532
\end{array}\right]^{T} \\
W_{B 4}=\left[\begin{array}{llllll}
0.3769 & 0.3958 & 0.0747 & 0.1449
\end{array}\right]^{T}
\end{gathered}
$$

Thus we obtain the weight of the criteria in the scheme hierarchy associated with those in the target hierarchy as follows:

$$
\begin{aligned}
& W=\left[\begin{array}{lllll}
0.0885 & 0.1394 & 0.1766 & 0.0696 & 0.0204
\end{array}\right. \\
& \begin{array}{llllll}
0.0388 & 0.0198 & 0.0209 & 0.045 & 0.209
\end{array} \\
& \begin{array}{llllll}
0.0087 & 0.0185 & 0.0066 & 0.0052 & 0.0053
\end{array} \\
& \begin{array}{lllll}
0.0881 & 0.0723 & 0.0261 & 0.0323 & 0.0237
\end{array} \\
& \begin{array}{lllllll}
0.0134 & 0.0144 & 0.0251 & 0.006 & 0.0123 & 0.0021]^{T}
\end{array}
\end{aligned}
$$

\subsection{TOPSIS Evaluation Algorithm}

Assume that the criteria in the scheme hierarchy of three EWCCSs s1, s2 and s3 are given in Table 5-8. 
Table 5. The Criteria C11- C17 in the Scheme Hierarchy of Three EWCCSs

\begin{tabular}{llllllll}
\hline & $\mathrm{C} 11$ & $\mathrm{C} 12$ & $\mathrm{C} 13$ & $\mathrm{C} 14$ & $\mathrm{C} 15$ & $\mathrm{C} 16$ & $\mathrm{C} 17$ \\
$\mathrm{~s} 1$ & $\operatorname{good} 3$ & 90 & 1 & 0.75 & 0.5 & 0.3 & fair \\
$\mathrm{s} 2$ & $\operatorname{good} 5$ & 80 & 6 & 0.9 & 0.1 & 0.2 & $\operatorname{good} 4$ \\
$\mathrm{~s} 3$ & good1 & 100 & 3 & 0.8 & 0.6 & 0.3 & $\operatorname{good} 2$ \\
\hline
\end{tabular}

Table 6. The Criteria C21- C28 in the Scheme Hierarchy of Three EWCCSs

\begin{tabular}{lllllllll}
\hline & C21 & C22 & C23 & C24 & C25 & C26 & C27 & C28 \\
\hline s1 & good3 & 0.3 & good1 & $\operatorname{good} 4$ & 8 & 9 & good2 & poor4 \\
s2 & good5 & 0.15 & $\operatorname{good} 4$ & $\operatorname{good} 3$ & 10 & 12 & $\operatorname{good5}$ & $\operatorname{good} 3$ \\
s3 & good4 & 0.15 & $\operatorname{good} 3$ & $\operatorname{good} 3$ & 7 & 10 & $\operatorname{good} 4$ & $\operatorname{good} 1$ \\
\hline
\end{tabular}

Table 7. The Criteria C31- C37 in the Scheme Hierarchy of Three EWCCSs

\begin{tabular}{llllllll}
\hline & $\mathrm{C} 31$ & $\mathrm{C} 32$ & $\mathrm{C} 33$ & $\mathrm{C} 34$ & $\mathrm{C} 35$ & $\mathrm{C} 36$ & $\mathrm{C} 37$ \\
\hline $\mathrm{s} 1$ & 10 & 3 & 3 & 0.5 & 0.1 & fair & $\operatorname{good} 4$ \\
$\mathrm{~s} 2$ & 15 & 6 & 4 & 0.2 & 0.1 & $\operatorname{good} 4$ & $\operatorname{good} 3$ \\
$\mathrm{~s} 3$ & 13 & 8 & 2 & 0.1 & 0.2 & $\operatorname{good} 2$ & $\operatorname{good} 2$ \\
\hline
\end{tabular}

Table 8. The Criteria C41- C44 in the Scheme Hierarchy of Three EWCCSs

\begin{tabular}{lllll}
\hline & C41 & C42 & C43 & C44 \\
\hline s1 & poor4 & fair & poor3 & 3 \\
s2 & good4 & good3 & good3 & 6 \\
s3 & good 1 & poor5 & fair & 9 \\
\hline
\end{tabular}

According to (2) and Table 1, Tables 5-8 can be changed into a decision making matrix in the form of the interval number, respectively, as follows:

$$
\begin{aligned}
& Y_{1}=\left[\begin{array}{ccccccc}
{[0.7,0.85]} & {[0.5,0.5]} & {[0,0]} & {[0,0]} & {[0.2,0.2]} & {[1,1]} & {[0.4,0.6]} \\
{[1,1]} & {[0,0]} & {[1,1]} & {[1,1]} & {[1,1]} & {[0,0]} & {[0.9,0.95]} \\
{[0.55,0.7]} & {[1,1]} & {[0.4,0.4]} & {[0.33,0.33]} & {[0,0]} & {[1,1]} & {[0.7,0.85]}
\end{array}\right] \\
& Y_{2}=\left[\begin{array}{cccccccc}
{[0.8,0.9]} & {[0,0]} & {[0.55,0.7]} & {[0.9,0.95]} & {[0.33,0.33]} & {[0,0]} & {[0.7,0.85]} & {[0.3,0.45]} \\
{[1,1]} & {[1,1]} & {[0.9,0.95]} & {[0.8,0.9]} & {[1,1]} & {[1,1]} & {[1,1]} & {[0.8,0.9]} \\
{[0.9,0.95]} & {[1,1]} & {[0.8,0.9]} & {[0.8,0.9]} & {[0,0]} & {[0.33,0.33]} & {[0.9,0.95]} & {[0.55,0.7]}
\end{array}\right] \\
& Y_{3}=\left[\begin{array}{ccccccc}
{[0,0]} & {[0,0]} & {[0.5,0.5]} & {[0,0]} & {[1,1]} & {[0.4,0.6]} & {[0.9,0.95]} \\
{[1,1]} & {[0.6,0.6]} & {[1,1]} & {[0.75,0.75]} & {[1,1]} & {[0.9,0.95]} & {[0.8,0.9]} \\
{[0.6,0.6]} & {[1,1]} & {[0,0]} & {[1,1]} & {[0,0]} & {[0.7,0.85]} & {[0.7,0.85]}
\end{array}\right] \\
& Y_{4}=\left[\begin{array}{cccc}
{[0.3,0.45]} & {[0.4,0.6]} & {[0.2,0.3]} & {[0,0]} \\
{[0.9,0.95]} & {[0.8,0.9]} & {[0.8,0.9]} & {[0.5,0.5]} \\
{[0.55,0.7]} & {[0.4,0.55]} & {[0.4,0.6]} & {[1,1]}
\end{array}\right]
\end{aligned}
$$


Then the whole decision making matrix in the form of the interval number is obtained as

$$
Y=\left[\begin{array}{llll}
Y_{1} & Y_{2} & Y_{3} & Y_{4}
\end{array}\right]
$$

Based on the above $Y$, the weight vector (15) and the formulas (11)-(13), we can obtain the weight distance from every evaluated system $s_{i}$ to the ideal solution and the negative ideal solution, respectively, as follows:

$$
D^{+}=\left[\begin{array}{lll}
0.7762 & 0.2533 & 0.3809
\end{array}\right]
$$

and

$$
D^{-}=\left[\begin{array}{lll}
0.4224 & 0.9542 & 0.8212
\end{array}\right]
$$

According to (14), we can calculate the approaching degree $Z_{i}$ for every evaluated system $s_{i}$ and write them in the vector form as follows:

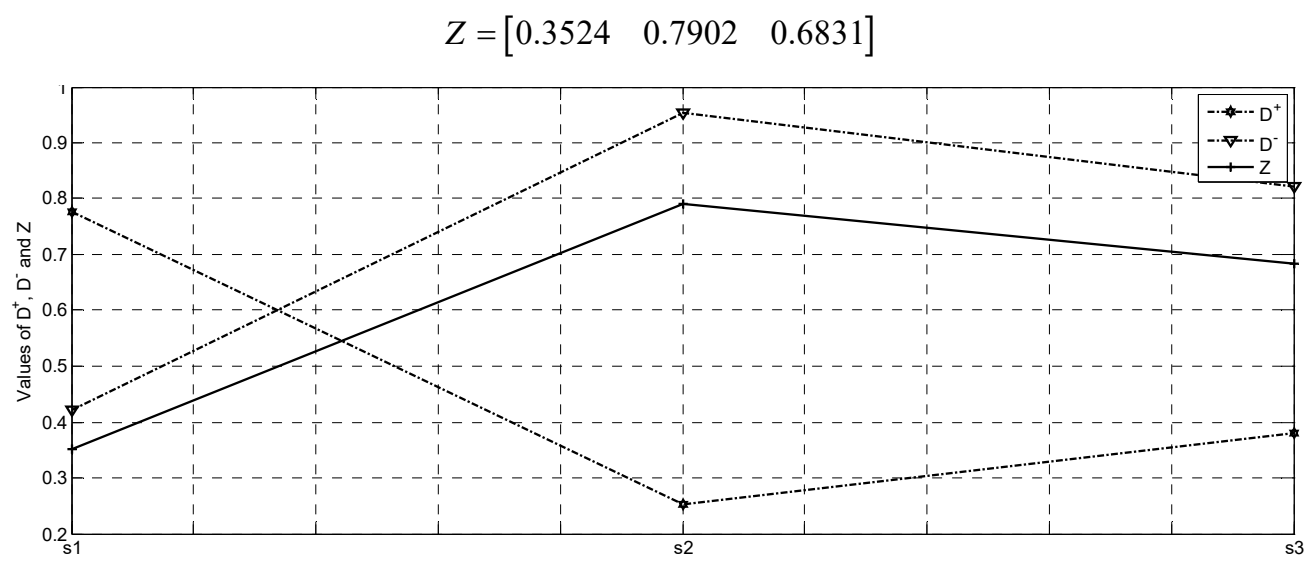

Figure 6. Values of $D^{+}, D^{-}$and $Z$

From Figure 6, we can obtain the sort order of effectiveness evaluation for three EWCCSs as follows:

$$
s_{2}>s_{3}>s_{1}
$$

According to the analysis of the experts, we can know that the effectiveness evaluation of three EWCCSs is same with the actual results.

\section{Conclusions}

Firstly, we establish the hierarchy structure of the electronic warfare command and control system and apply the AHP method to calculate the weights of the hybrid multiple attributes with the proposed hierarchy structure. Secondly, we use the interval number to present the fuzzy ability of hybrid multiple attributes and establish the decision matrix with the interval numbers. And then, according to a new definition for the distance between two interval numbers, the TOPSIS algorithm based on the ideal solution and the negative ideal solution is applied to calculate the effectiveness values and obtain the sort order of the evaluated systems. Finally, a numerical example of three electronic warfare command and control systems and its simulation results show that the proposed HMADM TOPSIS algorithm of effectiveness evaluation for the electronic warfare command and control system is simple and effective. 


\title{
Acknowledgements
}

This work was financially supported by the Open Project Foundation of the State Key Laboratory of CEMEE (CEMEE2015K0302B).

\section{References}

[1] J. Zhang, "Research on performance evaluation methods", Beijing: National Defense Industry Press, (2009).

[2] X. L. Yang, "Research and application of theory and method for hybrid multiple attribute decision making", Master's degree thesis of Huazhong Normal University, (2007).

[3] G. S. Wang and Z. F. Qi, "AHP Effectiveness Evaluation of Electronic Warfare Command and Control System under Complex Electromagnetic Environment", Advanced Materials Research, vol. 989, no. 3212, (2014).

[4] Z. F. QI and G. S. Wang, "Effectiveness evaluation of electronic warfare command and control system based on grey AHP method", Journal of Chemical and Pharmaceutical Research, vol. 6, no. 7, (2014).

[5] Z. F. QI and G. S. Wang, "Grey Synthetic Relational Analysis Method-based Effectiveness Evaluation of EWCC System with Incomplete Information”, Applied Mechanics and Material, vol. 638, no. 2409, (2014).

[6] F. M. Peng, "Aerial targets threat evaluation method based on Vague set TOPSIS", Electronic Optics and Control, vol. 10, no. 17, (2010).

[7] X. Wang, "Compromise sorting method for electronic warfare target threat assessment", Electronic Optics and Control, vol. 8, no. 10, (2013).

[8] W. P. Wang, "Research on the linguistic information multi-criteria decision making based on vague sets", Beijing: Economic Science Press, (2013).

[9] Z. S. Hua, Y. Y. Wu and X. Y. Xu, "A new method of consistency regulation for the AHP judgment matrix", Systems Engineering and Electronics, vol. 1, no. 25, (2003).

[10] K. Zhang and D. Y. Zhou, "Application of TOPSIS Based on Entropy and GD-AHP in Evaluating Sequence of Air Target Threat", Journal of System Simulation, vol. 7, no. 20, (2008).

[11] X. Tan, Y. F. Gao and Y. W. Chen, "New method for solving interval multi-attribute decision making problem", Systems Engineering and Electronics, vol. 7, no. 29, (2007).

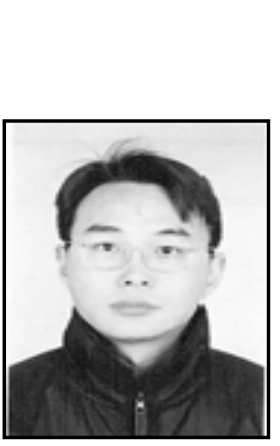

\begin{abstract}
Authors
Zong-Feng Qi, he received his Master Degree in System Engineering from National University of Defense Technology. $\mathrm{He}$ is currently a Senior Engineer of the State Key Laboratory of Complex Electromagnetic Environment Effects on Electronics and Information System, Luoyang, ROC. His current research interest includes effectiveness evaluation.
\end{abstract}

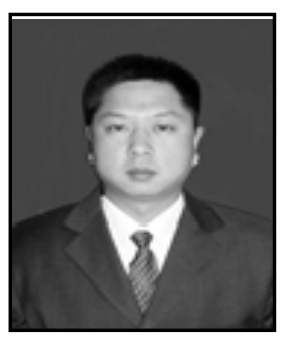

Guo-Sheng Wang, he received his $\mathrm{PhD}$ in Control Theory and Control Engineering from Harbin Institute of Technology in 2004. He is currently an associated professor of Department of Control Engineering, Academy of Armored Force Engineering, Beijing and ROC. His current research interest includes effectiveness evaluation. 